\title{
The Wuhan 2019 Human Coronavirus (CoV) Outbreak: Are We at the Edge of Global Pandemic?
}

\author{
Hamid Hussain* \\ Consultant, Dubai Health Authority, UAE \\ *Corresponding author: Hamid Hussain, Consultant, Dubai Health Authority, UAE, E-mail: hussainh569@gmail.com
}

Received: 25 Jan, 2020 | Accepted: 30 Jan, 2020 | Published: 31 Jan, 2020

Citation: Hussain H (2020) The Wuhan 2019 Human Coronavirus (CoV) Outbreak: Are We at the Edge of Global Pandemic? J Clin Case Stu 5(1): dx.doi.org/10.16966/2471-4925.197

Copyright: (c) 2020 Hussain $\mathrm{H}$. This is an open-access article distributed under the terms of the Creative Commons Attribution License, which permits unrestricted use, distribution, and reproduction in any medium, provided the original author and source are credited.

\section{Current Episode of nCoV2019}

Since the notification to $\mathrm{WHO}$ of the first suspected cases of nCoV2019 on 31 December 2019, the story evolution looks like as if we are currently thrown at the edge of global health crisis. The continuation of successive episodes of emerging pathogens places the world on the edge of unprecedented threat. The current $\mathrm{CoV}$ epidemic has managed to expand the scope of its spread in a remarkable way to many countries and diverse population groups without visible indicators showing the possibility of limiting the spread of the outbreak and narrowing its scope. Thus, the cosmic community finds itself with two main issues, the first is the weak capabilities of prediction and preparedness, and the second is the inability to contain early outbreaks using the resources available for national and local health systems [1-3].

\section{Lack of Prediction and Preparedness at National Health Systems}

The experience of exposure to transboundary hazards in the last three decades argues that local and national health systems are inadequate. The latter must be able, technically to simulate the underlying and imminent danger that poses a challenge to the global public health system. This is evident as the world witnessed the spread of highly pathogenic H5N1 influenza, SARS, Ebola, Zika virus and the Middle East Respiratory Syndrome (MERS-CoV) has caused transformations in public health systems with coordination and integration with international public health system response [4].

\section{Outbreak Morbidities and Mortalities}

Time after time, the numbers and the facts related to an outbreak, whether current or previous outbreaks reflect that we often find ourselves with growing and accelerating numbers of injuries that expand in their temporal and spatial dimensions that exceeds the available capabilities to reduce it despite the application of all available protocols. There is a need for a new look with innovative mechanisms for confrontation and response. The course of outbreaks often reflects frightening statistics on the level of disease incidence and prevalence and mortality rates among different population groups. Thinking outside the box in an unfamiliar way is needed [5-8].

\section{Economic Implications}

In most times, cross-border outbreaks place the fate of the world on the edge of the threat and economic overburden due to its direct impact on the movement of trade and tourism-related activities as well as productive activities with thousands of people out of the cycle of production and productive economic activity. Thus, the burdens multiply and take other forms that are not limited to the direct health and financial burdens required to deal with the disease, but rather extend to the burdens of the global economic slowdown and its deterioration $[9,10]$.

\section{Gaps in the International Public Health System}

The international public health system needs a new leadership vision-based largely on the ability to predict and initiate rather than wait and respond. This may be achieved by linking vital information systems with public health sciences and bringing epidemiology side by side with information and data management techniques, and artificial intelligence, in addition to genetic studies related to epidemic mutant viruses. The international health system has made significant steps towards the principles of early prevention and avoiding the underlying and imminent dangers. We can say that one of the most important reasons for the inability of the international global health systems to anticipate and challenge epidemics before they occur is that we are not yet able to use the available resources effectively and benefit from the data despite the tremendous progress in the sciences and technologies that humankind has achieved $[11,12]$.

\section{References}

1. WHO (2020) Statement on the meeting of the IHR (2005) Emergency Committee regarding the outbreak of novel coronavirus (2019nCoV). World Health Organization, Geneva, Switzerland.

2. National Center for Immunization and Respiratory Diseases (NCIRD) (2020) 2019 Novel Coronavirus, Wuhan, China. Centers for Disease Control and Prevention (CDC), USA.

3. Wu F, Zhao S, Yu B, Chen Y-M, Wang W, et al. (2020) Wuhan seafood market pneumonia virus isolate Wuhan-Hu-1, complete genome. Gen Bank MN908947.3. 
4. Disease outbreak news (2020) Pneumonia of unknown cause-China. World Health Organization, Geneva, Switzerland.

5. Schnirring L (2020) Report: Thailand's coronavirus patient didn't visit outbreak market. CIDRAP News, Center for Infectious Disease Research and Policy (CIDRAP), Minneapolis.

6. Chinese Center for Disease Control and Prevention (China CDC). Beijing, China.

7. Huaxia (2020) New-type coronavirus causes pneumonia in Wuhan: expert. Xinhua News, Xinhua, Beijing.

8. CoV2020. Platform.gisaid.org.
9. Hui DS, Azhar El, Madani TA, Ntoumi F, Kock R, et al. (2020) The continuing 2019-nCoV epidemic threat of novel corona viruses to global health-The latest 2019 novel coronavirus outbreak in Wuhan, China. Int J Infect Dis 91: 264-266.

10. H5N1 (2020) Wuhan: Experts explain the latest bulletin of unknown cause of viral pneumonia. Wuhan Municipal Health Committee.

11. Phylogeny of SARS-like betacoronaviruses. Nextstrain.

12. Wong ACP, Li X, Lau SKP, Woo PCY (2019) Global Epidemiology of Bat Corona viruses. Viruses 11: E174. 